\title{
Richard N. Adams
}

\author{
Richard N. Adams
}

Jorge Solares

Universidad de San Carlos de Guatemala

*Autor al que se dirige correspondencia: jorgesolario@gmail.com

El 11 de septiembre del año 2018 falleció el conocido antropólogo estadounidense Richard N. Adams. Me atrevería a decir que Guatemala constituyó su segunda patria, y en cuanto a escenario de su trabajo antropológico, indudablemente su primera. Tenía 94 años, falleció respirando escenarios como el del Lago de Atitlán, en cuyas riberas se asentó en definitiva en compañía de su eterna compañera, Betty.

Produjo un amplio caudal de obras antropológicas, básicamente sobre Guatemala y fundamentalmente en torno al fenómeno de la etnicidad. Porque en efecto, lo étnico va de principio a fin en sus obras $\mathrm{y}$ en su obra, independientemente del tema que en su torno apareciera como el protagonista. Interpretaba lo étnico tanto en observación empírica, como en razonamiento teórico, desde el microcosmos de la localidad hasta el macrocosmos de la nación y la internacionalidad, intentando encontrar la explicación medular de su esencia ya fuera desde el evolucionismo, el estructuralismo, lo energético estructural e inclusive, el materialismo dialéctico. Y recalco lo de "inclusive", toda vez que pudo ser tal enfoque incongruente con quien laboró para entidades estatales de su país de origen, y ello en plena Guerra Fría y por añadidura en el "traspatio", de los mismos, hoy rebautizado como "El Triángulo Norte”.

Habiendo principiado a su edad temprana en un lugar como la perturbadora Guatemala de la Revolución de Octubre de 1944, su orientación teórica no fue unilineal sino más bien sujeta a ciertas dispersiones, y él lo reconoce al identificarse a sí mismo como alguien que anduvo "rebotando"...en teorías políticas se entiende. En 1951, recién graduado y ya doctorado en antropología, fue por Antonio Goubaud Carrera, antropólogo y embajador guatemalteco en los Estados Unidos, invitado a venir a Guatemala para promover el interés por el estudio antropológico, tanto en la Universidad de San Carlos de Guatemala (para impartir cursos sobre antropología aplicada) como en otras instituciones estatales. De la primera menciona que no redundó en una buena relación, pero no indica con claridad concreta por qué. Después se vinculó al Instituto de Nutrición de Centroamérica y Panamá (Incap) en programas de alimentación para el área rural, iniciándose así, investigaciones antropológico-sociales sobre programas de nutrición en América. Continuó articulándose con otras juveniles instituciones creadas por los gobiernos revolucionarios, tales como el Instituto Indigenista Nacional (IIN, cancelado y desmantelado bastantes años después por el gobierno democratacristiano de Vinicio Cerezo Arévalo) y el Incap, instituciones de las que salió su estudio "Un análisis de las creencias y prácticas médicas en un pueblo indígena de Guatemala". También sostuvo relación con el Seminario de Integración Social Guatemalteca (SISG), del cual afirma haber sido inspirador, junto con los antropólogos estadounidenses Kalman Silvert, John Gillin y el académico guatemalteco Jorge Skinner Klee, institución que años después fue también suprimida y desmontada por el mismo gobierno del presidente Vinicio Cerezo.

Adams produjo gran cantidad de obras antropológicas especialmente sobre Guatemala, destacándose de acuerdo con su propia opinión: Introducción a la Antropología Aplicada (escrita para el Incap y editada por el SISG). Luego, Encuesta sobre la Cultura de los Ladinos en Guatemala (SISG). Dicha obra desató críticas por haber hipotetizado una inexorable tendencia demográfica regresiva de la población indígena desde el Siglo XIX. Después vino Crucifixion by Power (1960), ensayos sobre la estructura social guatemalteca 1944-66 que trata de la realidad nacional durante 
quince años y donde expuso que "la estructura de poder estaba crucificando al pueblo guatemalteco". Se la considera una de las más influyentes obras escritas en inglés sobre Guatemala, donde no se ha difundido por no estar traducida.

A pesar de las tendencias dominantes y de la época en que fue formándose en Estados Unidos, Adams no era culturalista, más bien penetró en las estructuras sociales y de poder de la nación y de las etnicidades, buscando encontrar relaciones causales y explicativas del fenómeno y su evolución. Éste es un tema, según nuestro criterio, que sigue demandando una esmerada atención científica pues la contribución socioantropológica a la ciencia política sería de alto beneficio para la comprensión de la conflictiva situación política de nuestro país.

Pero el peculiar quehacer y estilo del Dr. Adams fue atrayéndole, especialmente a él, un mar de sospechas en el medio intelectual nacional y más allá. Concretamente, fue viéndosele como un científico encubiertamente enviado por el Gobierno de los Estados Unidos, en el torbellino guatemalteco dentro del contexto proceloso de la Guerra Fría. Varias razones subjetivas fueron atrayéndole tal sospecha, y otras menos subjetivas como el haber firmado con pseudónimo un estudio sobre "ideologías comunistas" en prisioneros políticos apresados por Castillo Armas. A pesar de sus explicaciones ante el "destape", la sospecha había germinado. Por todo esto, como pocos antropólogos extranjeros en Guatemala, Richard N. Adams suscitó enconadas y controversiales opiniones. Pero por otra parte, la estrecha confianza que le depararon figuras conspicuas de la izquierda intelectual guatemalteca, vienen a constituir un contrapeso. ¿Quién acierta? Este no es el momento ideal para tratar de desentrañar el asunto que en todo caso podría ser motivo de análisis por parte de científicos especializados y para beneficios concretos, si es que tal pesquisa conservara aún utilidad. Por nuestra parte y por de pronto, ofrezco aquí lo expresado por Adams en una entrevista que se le hizo en 1993 para una revista no especializada que no consignó el nombre de quien entrevistó, y en la cual Adams ofrece su opinión sobre la situación política de Guatemala durante el gobierno transicional de Ramiro de León Carpio:

No hay ninguna duda de que es mejor que hace diez años [1983]. El nivel de violencia ya no es el mismo y se pueden publicar trabajos que en esa época era imposible hacerlo. Hay gobiernos corruptos pero civiles.
Actualmente, la corrupción es compartida entre más personas, no sólo entre los militares, sin embargo el factor más decisivo y lamentable es que el nivel de pobreza de la población aumenta, la economía no está creciendo de acuerdo a las necesidades del país. Además, no se está libre de la dominación militar y mientras continúe esta situación, existe la posibilidad de retornar al sistema político de unas décadas atrás. [Nota Bene: poner atención a su apreciación de la influencia militar, tres décadas después de su controversial época guatemalteca].

Quien lo entrevistó introdujo la entrevista así:

El nombre del antropólogo Richard Adams es sinónimo de controversia en nuestro país. Para determinados sectores es un personaje ligado a la derecha y para otros a la izquierda. Sin embargo, él mismo asegura que no sigue una línea ideológica vertical...

La entrevista mencionada se cierra con la pregunta ¿Qué significa Guatemala para usted? Respondió: “Un microcosmos del problema mundial. Aquí se pueden ver y vivir problemas étnicos, sociales, económicos, corruptos, educacionales, de salud y otros que no se ven en conjunto en otros países."

Hasta aquí el Dr. Adams. Mi acotación: Para él, quien nos conoció tanto, constituíamos una nación compleja y complicada. Y agrego: El Dr. Adams fue un incansable observador de Guatemala. Escudriñó con amplitud y profundidad antropológico-social adentro del ámbito político nacional. Dueño de una visión fina y perceptiva, inductora y deductiva, de análisis depurado y predicción política que desde el ámbito y nivel micro se extendía hasta el macro, como viendo una mansión desde la cocina, hilando hechos para encontrar sus relaciones e hilando relaciones para encontrar explicaciones y de ahí, el ámbito de las "predicciones" o mejor, "conjeturas razonadas".

Si fue una figura controversial en la antropología social en Guatemala, a la vez constituyó un verdadero referente internacional en el campo de las ciencias sociales, tanto teóricas como aplicadas para países de América Latina. Justamente en ello fue donde entró de lleno a la controversia que impregnó una buena parte de su vida. Su figura generó contrapuntos: si en las vertientes de la izquierda de entonces hubo voces acres contra él, también las hubo muy favorables. La persona era compleja y altamente polémica. Él mismo insinuó reconocerlo cuando se definió (repitiendo lo escrito en un principio) como alguien que en etapas 
formativas en estos suelos anduvo "rebotando". Su estilo plenamente maduro parece confirmarlo y nos lleva a la frase de Buffon: El estilo es el hombre.

Detengámonos aquí. Considero por de pronto más productivo no entrar en esas elucubraciones y en su lugar, penetrar en la lectura atenta de sus escritos sobre Guatemala pues siempre tendrán algo que nos sorprenderá positivamente. En otras palabras, la persona política ha estado en el tablero, pero no el profesional de las ciencias sociales cuya solvencia, creo yo, debe ser atentamente percibida. Quien se entregó tanto a nuestro país debe ser escuchado, leído, analizado y tal vez, ya no juzgado. 